

\title{
On the Effect of Carbon Content to the Mechanical Properties and Microstructure of Green Compacts Formed at above Ambient Temperature
}

\author{
Md. Mujibur Rahman, Sany Shahriman Md Nor, Hendri Yani Rahman \\ Department of Mechanical Engineering, Universiti Tenaga Nasional \\ Putrajaya Campus, Jalan IKRAM-UNITEN, 43000 Kajang, Malaysia \\ Tel.:+06-3-89287269,E-mail: mujibur@uniten.edu.my
}

\begin{abstract}
Friction force is generated during the generation of green compacts from metal powder, which obviously gives adverse effect to the mechanical properties and microstructure of the green compacts. In this study, fine carbon powder is used to minimize the interparticle as well as die wall frictions and as alloying element hence high density yet defect-free near-net shape or net shape mechanical components can be produced. Powder forming at elevated temperature is a relatively new technology hence the effect of carbon content is not fully explored yet. Therefore, a lab scale warm compaction rig is designed and fabricated which enabled the generation of green compacts at different forming load and temperature. The powder mass was prepared by mechanically mixing iron ASC 100.29 powder with different weight percent of fine carbon powder for different duration of time. The prepared powder mass was formed at different compaction temperature to generate green compacts for the purpose of mechanical testing and microstructure evaluation. The results revealed that the mechanical properties and microstructures of green compacts are affected by the carbon content, mixing time, as well as forming temperature. From this study, the suitable carbon content, mixing time, and forming temperature are identified for the production of high quality mechanical components.
\end{abstract}

Keywords- Hardness, ferrous material, powder metallurgy, die-wall friction.

\section{INTRODUCTION}

In the last three decades, a wide range of mechanical components especially for the use in various automotive parts have been developed for the production through powder route [1-2] where most of them are produced by the process called die compaction method either formed at room temperature or at elevated temperature. The production of solid components from powder by compaction and sintering in sequence is known as powder metallurgy [3-4], which has been existence since the early nineteen hundreds as a new generation of manufacturing process [2]. Generally, powder metallurgy products are used in wide range of industries such as in automotive [1-2], aerospace, power tool and household appliances. It has been identified that significant number of engineering components and parts were made from the shaped and sintered metal powders. This processing technique has become more important as it provides a lot of advantages than conventional fabrication techniques such as casting, forging, machining, etc [5]. This technique is better for the production of mechanical components with high precision compared to other production technologies [6].

The study of near-net-shape manufacturing through powder metallurgy route has become essential since there is need in cost reduction and improvement in mechanical properties [7-8] such as higher density, strength, etc. Therefore, the optimization between these two aspects, i.e., economics and mechanical properties has to be found simultaneously. This optimization suites excellently during this economic recession era and provides more reliable market value in longer time. A major advance in this technology is the warm forming process, which can utilize traditional powder forming equipment. The warm forming is defined as compaction of metal powder at elevated but below its re-crystallization temperature [9]. Generally, the warm powder forming process is influenced significantly by forming temperature. However, the precise and comprehensive research on other parameters such as loading mechanism and lubrication formulation widen the range of suitable forming temperature, thus broaden the possibility to explore more towards mechanical and microstructure behaviours of a compact as a function of forming parameters. 
During the compaction of powder mass in a rigid cylindrical die, only a portion of the axial load is transformed to radial direction. This radial component of the force can be quite substantial but does not reach the level of the axial force because the powder is not a liquid and has no hydraulic properties [10]. Aggregates of metallic particles are considered as frictional, nearly non-cohesive and granular [11]. When the load acts upon the powder mass in the die cavity, the powder mass deforms plastically, each of the particles fills the gap among them, which results in reduction of pores, means density of the powder mass increases. During compaction, powder exhibits strain or work hardening, the volume decreases and hardness increases [12].

Powder inside the die receives a large amount of load and due to the relative movement between the die wall and powder mass, friction force is generated during the compaction phase [13]. The green compacts, sometimes, may face the possibility of getting crack which is mainly due to the density gradient inside the green compacts resulted from the inhomogeneous density distribution [14]. Friction between powder particles and tooling such as the puncher surface and die wall results in nonuniform density distribution during this process [10].

During the densification of powder mass to become green compact, a considerable friction force is generated which is the major cause of density variation throughout the powder compact [15-16] and also affects the component deformation [17]. Inter-particle and particle/die wall friction also hinders pressure transmission and therefore produces density gradients inside the compact [18]. The friction force also generates considerable amount of heat that affects the compaction process generally, and material properties, specifically. Lubrications have been identified as suitable method to overcome this limitation. Lubrication is important to reduce friction both internally among powder particles and between powder mass and the die surface. Some additives are optional depending on the part manufacturer, which can reduce sintering time, improve microstructure and machinability [19]. An admixed lubrication where lubricant mixed together with the powder constituents is important method in achieving higher green density. Usually zinc stearate is used as lubricant in powder compaction; however its function is limited to $130^{\circ} \mathrm{C}$ due to its lower melting temperature [20].

In order to obtain the superior performance of the product generated through warm forming route, the lubricant should be forced out from the pore structure of the powder mass and lubricating the wall of the compaction tool, hence the ejection force can be reduced [21]. Another reason of delubrication is that it would otherwise create pores in the compact after sintering [8]. It is well-known that large pores have an adverse effect on the dynamic strength properties of the product [22-23]. Shrinkage, dimensional tolerance, fractional area, electrical conductivity, as well as surface finish are in direct relation to the lubricant, mainly on the level of porosity. Another problem in using the lubricant is that most of the lubricants used during cold compaction cannot be used during warm compaction, since they are found to be effective within a limited temperature range only. An ineffective lubricant considerably increases the wear of the compaction tool [21]. Therefore, alternative lubricant with higher melting temperature can be applied in minimizing the problems arise during sintering process.

Many industrial applications use iron as main powder that to be compacted because of its excellent material and mechanical properties. In industry, copper powder is often used for the infiltration of iron base compacts to decrease the pores and to improve the mechanical properties and aluminium powder is used as a material to achieve the weight reduction of the compacts [24]. Generally, carbon powder is used in industries as alloying element, to enhance the mechanical properties and dimensional stability of components produced. As a particulate lubricant, carbon powder assists the process of compaction by reducing the friction among iron powder particles so that the compaction pressure is exerted evenly in the container. This has become an advantage for the compaction process due to its lubricating nature and hardenability. This also has the relation with the porosity of the material, where carbon particles move rapidly into the gaps among iron particles due to its lower density which reduces the pores hence increases the contact between iron particles during compaction.

Activated carbon is a porous form of carbon manufactured from coconut shell, wood or coal [25], having melting point of about $3550^{\circ} \mathrm{C}$ [26], and therefore, is suitable for the compaction process with relatively low powder forming temperature. Carbon powder does not function as alloying element if the content is less than about $1.2 \mathrm{wt} \%$ [27], otherwise it functions as lubricant. Therefore, in order for carbon to function as lubricant, the range of carbon to iron powder is limited to only $0.7 \mathrm{wt} \%$. Therefore, this research aims to investigate only the behaviour of carbon as lubricant and its relationship to the forming temperature during powder compaction.

\section{MATERIALS AND METHOD}

This research used iron powder ASC 100.09 with particle size of 30-50 $\mu \mathrm{m}$ manufactured by Höganäs $\mathrm{AB}$ and fine activated carbon R4-W10 as lubricant or additive. The warm compaction process consists of five stages which are powder mixing with lubricant or additive, die filling with the powder mass, heating of the die and powder mass, compaction simultaneously by two-directional axial punches, and finally relaxation and ejection of the green compacts from the die cavity. Iron powder is first mixed with carbon powder ranged from 0.02 to 0.7 weight percent for 10,30 and 60 minutes. The powder mass is filled inside cylindrical die with hole diameter of $20 \mathrm{~mm}$ and length of $60 \mathrm{~mm}$. The die consists of 4 point heaters supplying 50 watts of electrical power. The top punch is brought close to the surface of the powder mass in order to have uniform forming temperature for die assembly. The powder mass is then heated up to prescribed temperature ranging from 30 to $200^{\circ} \mathrm{C}$. The simultaneous compaction carried out at different load value ranged from $60 \mathrm{kN}$ to $130 \mathrm{kN}$. Finally, the upper punch is released back to its initial position and the green part is ejected from the die by pushing the bottom punch to the upward direction.

The relative densities of the green compacts are calculated from the weight of the powder mass filled inside the die cavity and the dimensions of the die cavity. The hardness 
and strengths are measured using Rockwell Hardness Test Machine (FR-3, serial number: FR 3189) and universal testing machine (Instron 5567, serial number: P4716), respectively. In order to observe the microstructure of the green compacts, they are scanned at 50, 500 and 5000 magnification using Scanning Electron Microscopy (SEM) machine (The Quanta 400, serial number: 4022262 32071).

\section{RESULTS AND DISCUSSIONS}

Mechanical testing and microstructure analysis have been conducted in investigating the effect of forming temperature as well as weight percent of carbon content during densification process. Fig. 1 shows the relative density variations of green compacts with different carbon contents formed at different compaction parameters. It is evident that the relative density of green compact increases till the carbon content reaches about 0.3 to $0.4 \mathrm{wt} \%$ irrespective of their forming temperature. It is also observed that higher forming temperature gives higher relative density at every weight percent of carbon content except for $200^{\circ} \mathrm{C}$. This finding strengthens the established theory which stated that the deformation of metals can be looked upon as a thermally activated process where both the elastic and inelastic deformations are affected [28]. However, as a consequence of the expansion phenomenon of powder mass due to temperature increase above $180^{\circ} \mathrm{C}$, less compaction effect is obtained by applying the same forming load [29].

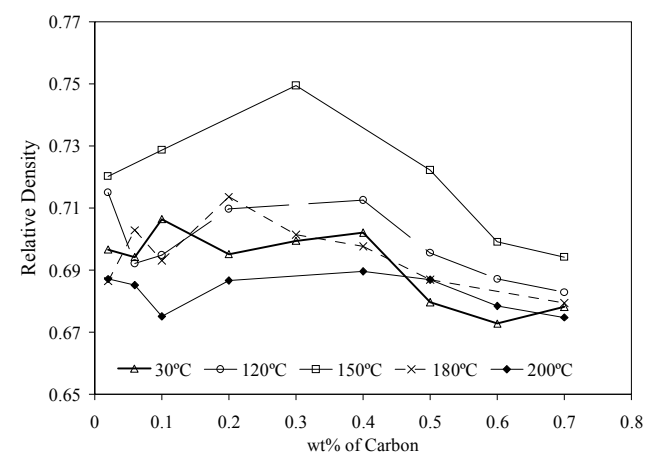

Fig. 1 Relative density variations of green compacts formed at $80 \mathrm{kN}$ compaction load

Fig. 2 shows that the strength of green compact increases as forming temperature increases while further carbon addition to more than $0.4 \mathrm{wt} \%$ gives reverse effect. At higher forming temperature, more dense packing order of iron occurs due to relocation of carbon powder thus promoting better inter-particle relation among iron particles that lead to increase in green strength. However, large amount of carbon powder at low temperature results in unnecessary carbon powder trapped in between the gaps of iron powder particles inside the green compact. In addition, the shape of carbon particles becomes obstacle for the movement of iron particles when large amount of carbon powder is present [30].

The hardness of green compacts is also affected by the forming temperature and carbon content as shown in Fig. 3. As carbon content is increased, more carbon particle is relocated at the sides of the green compacts due to the lower density of carbon compared to iron which resulted in lower hardness of the green compacts. Fig. 4 and Fig. 5 show the relative density of green compacts at different forming load and temperature. As loading increases, rapid movement and rearrangement of iron and carbon particles occur. The carbon particles slide out from the powder mass during this process which resulted free space to be occupied by iron particles [31]. Therefore, it can be observed that green compacts without carbon content have lower relative density value compared to green compacts with $0.1 \mathrm{wt} \%$ carbon content. This proves that at this range of forming temperature which is far below the melting temperature of carbon, there is no chemical bonding between iron and carbon particles. However, this finding also proves that carbon acts as good lubricant in the range of 0.1 to $0.4 \mathrm{wt} \%$ as its main function is to promote free space for iron particle rearrangement as can be seen in density increment.



Fig. 2 Flexure stress variations of green compacts formed at $80 \mathrm{kN}$ compaction load



Fig. 3 Hardness of green compacts formed at $80 \mathrm{kN}$ compaction load



Fig. 4 Relative density of green compacts formed at different compaction temperature 




Fig. 5 Relative density of green compacts mixed with different carbon content and formed at different compaction temperature

The effects of forming load and temperature at different carbon content are shown in Fig. 6. As shown earlier in Fig. 3 , more carbon content resulted softer green compact because more carbon particles trapped at the surface of the compact. It is evident that, increasing the forming load above $100 \mathrm{kN}$ did not give much effect to the hardness due to rapid movement of carbon particles even at lower forming load. As in relative density variation, this range of forming temperature does not show any sign of major influence of carbon behavior to the mechanical properties of green compacts.

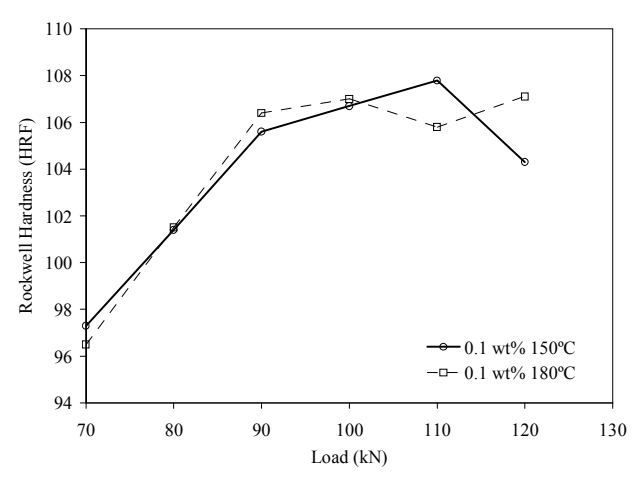

Fig. 6 Effect of forming temperature to the hardness of green compacts

The flexure strengths of green compacts are found to have the almost same trend despite the different forming load and carbon content (Fig. 7). However, at higher forming temperature with same carbon content, i.e., $0.4 \mathrm{wt} \%$ the green strength is found to be increased. This finding confirms previous arguments that, at this range of forming temperature, carbon did not interact chemically with iron powder. It just provides free space due to its movement thus increasing packing order of iron powder stimulated by the loading effect. Hence, it can be highlighted that forming temperature affects only inter particle rearrangement of iron powder. Therefore, at the presence of large amount of carbon powder, density, strength and hardness of green compacts are reduced. However, if longer mixing time is taken into consideration (Fig. 8), where more even carbon powder distribution occurs in the powder mass before compaction, the density can be increased despite of carbon content.

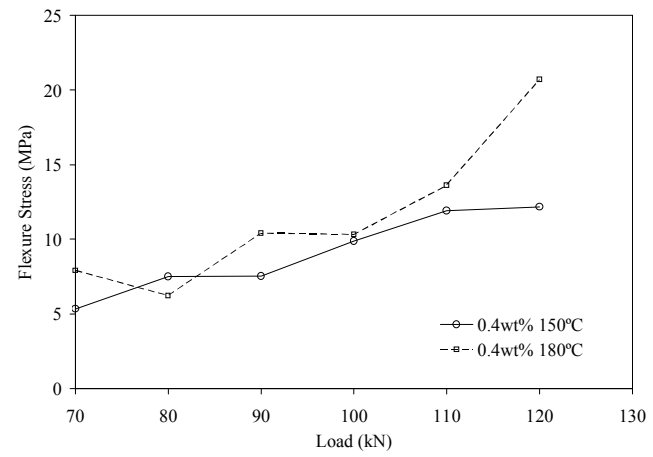

Fig. 7 Effect of forming temperature to the strength of green compacts

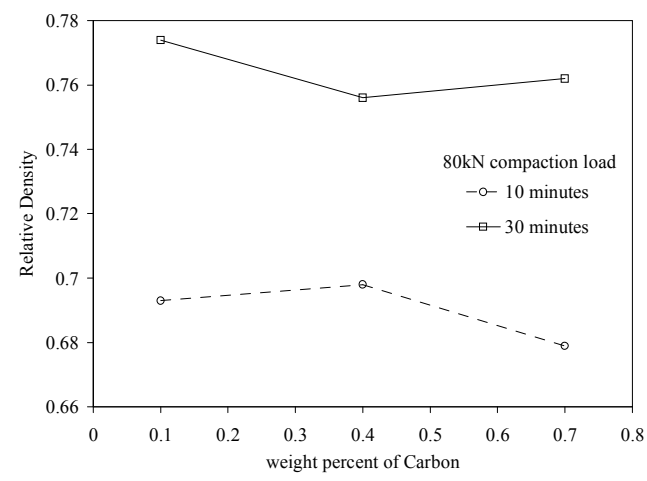

Fig. 8 Effect of mixing time to the relative density of green compacts

Micrographs (Fig. 9) show that at both room and elevated forming temperature, no signs of particle adhesion between iron and carbon particles are observed. This is the evidence of the less effectiveness of forming temperature at this range to the density, strength and hardness of green compacts [3236]. Fig. 10 shows that higher carbon content resulted in more carbon powder are localized at certain points regardless of its forming temperature. It is also evident that almost perfect particle fusion which did not leave any significant particle boundaries for the compaction at $180^{\circ} \mathrm{C}$ compared to compaction at $30^{\circ} \mathrm{C}$ (Fig. 10C, D). In addition, particle boundaries and micropores can be observed for the compaction at $30^{\circ} \mathrm{C}$. This is the evidence of the influence of forming temperature only on the iron particles where carbon does not have any significant effect for the compaction at room temperature $\left(30^{\circ} \mathrm{C}\right)$. 


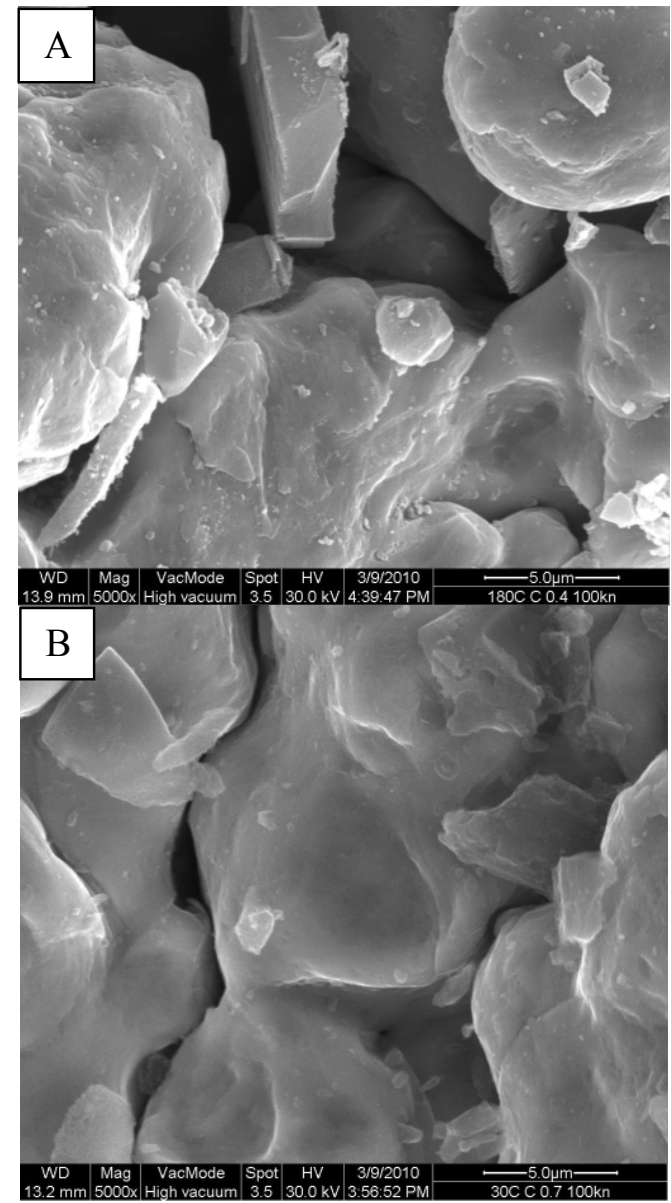

Fig. 9 Micrographs of green compacts at different carbon content and forming temperature, (A) $180^{\circ} \mathrm{C} ; 0.4 \mathrm{wt} \%$ Carbon, (B) $30^{\circ} \mathrm{C} ; 0.7 \mathrm{wt} \%$ Carbon

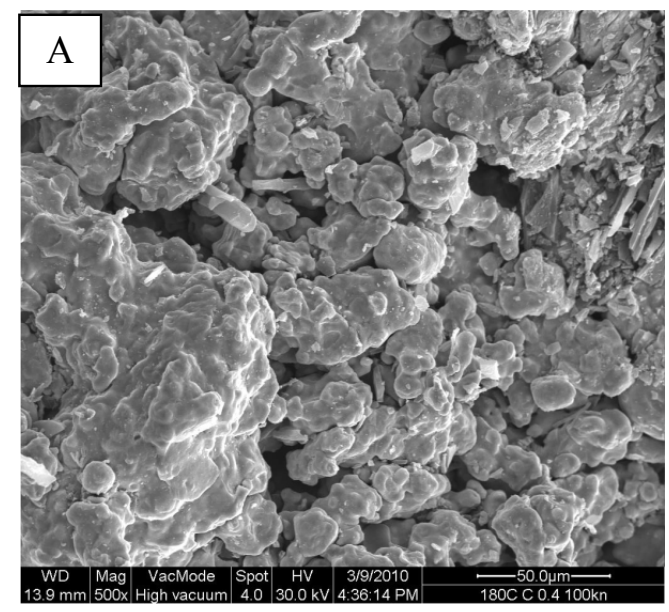

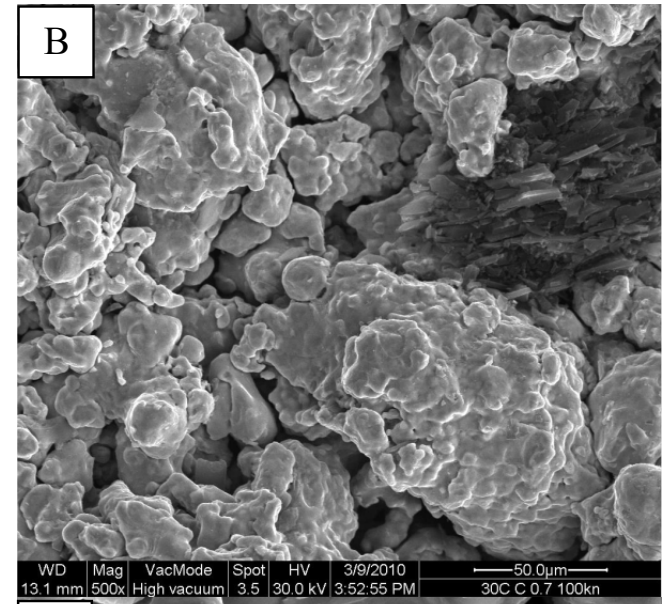
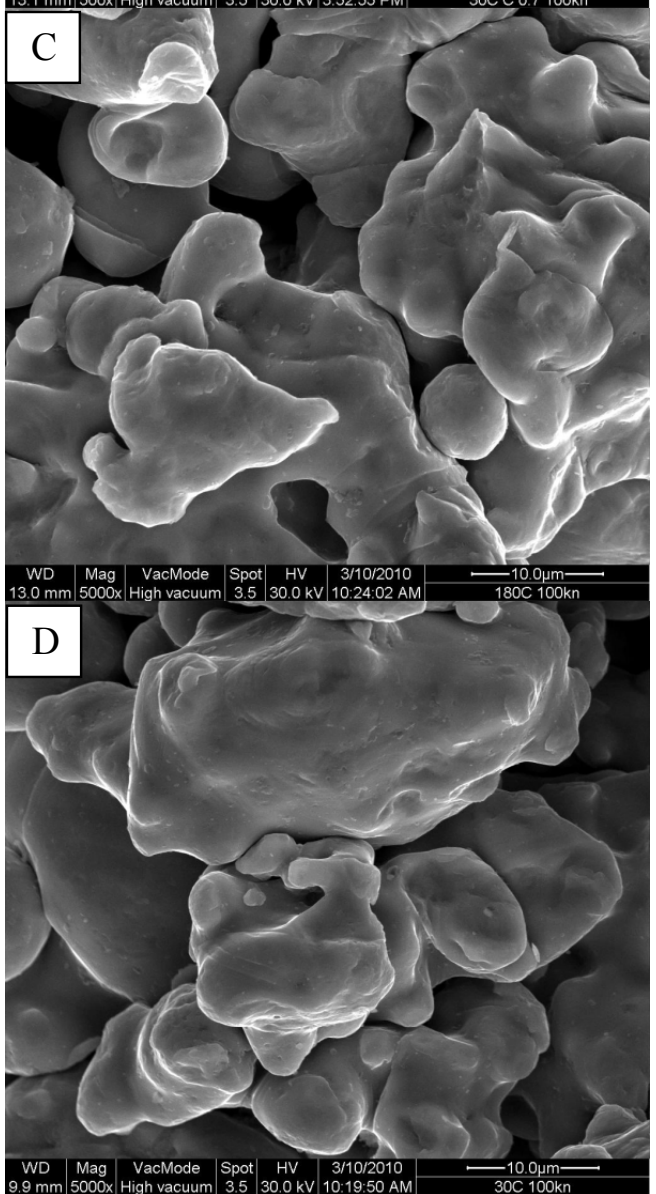

Fig. 10 Micrographs of green compacts with and without carbon content at different forming temperature, (A) $180^{\circ} \mathrm{C} ; 0.4 \mathrm{wt} \%$ Carbon, (B) $30^{\circ} \mathrm{C} 0.7$; wt $\%$ Carbon, (C) $180^{\circ} \mathrm{C}$; without Carbon, (D) $30^{\circ} \mathrm{C}$; without Carbon

\section{CONCLUSIONS}

An experimental investigation on the effect of forming temperature and the addition of fine carbon powder to the density, hardness, bending strength, and microstructure of green compacts formed at above ambient temperature was presented. The research concluded that fine carbon powder is suitable as admixed lubricant in powder compaction process at elevated temperature. However, the content of carbon powder must be limited to 0.4 weight percent only as further addition resulted in poor green strength and hardness 
that might not be suitable for further handling such as sintering, etc. It is evident from microstructure analysis that, interparticle bonding among iron powder particles and their movement can be improved by elevated forming temperature, optimum loading and better carbon rearrangement.

\section{ACKNOWLEDGMENT}

The authors are grateful to the Ministry of Science and Technology and Innovation (MOSTI) Malaysia for funding this research project under 03-02-03-SF0146. Thanks to Universiti Tenaga Nasional for the permission given to the authors to conduct the necessary testing.

\section{REFERENCES}

[1] D. Whittaker, "Powder metallurgy applications in the automotive industry," in Proceeding World Conference on Powder Metallurgy., 1990, paper 90, p. 109-116.

[2] A. K. Ariffin, M. M. Rahman, and A. Jumahat, "An experimental investigation of warm powder compaction process," in BSME-ASME International Conference on Thermal Engineering, 2002.

[3] K. T. Kim, and J. H. Cho, "A densification model for mixed metal powder under cold compaction," International Journal of Mechanical Sciences, vol. 43, pp. 2929-2946, 2002.

[4] E. Hryha, P. Zubko, E. Dudrova', L. Pes`ek, and S. Bengtss, "An application of universal hardness test to metal powder particles," Journal of materials processing technology, vol. 209, pp. 2377-2385, 2009.

[5] P. Chakravarthy, U. Chakkingal, and P. Venugopal, "Influence of temperature on the forming limit diagrams of sintered $\mathrm{P} / \mathrm{M}$ preforms of steel," Materials Science and Engineering A, vol. 485, pp. 395402, 2008.

[6] G. F. Bocchini, "Warm compaction of metal powders: why it works, why it requires a sophisticated engineering approach," Powder Metallurgy, vol. 42(2), pp. 171-180, 1999

[7] D. Uzunsoy, "The characterization of PM 304 stainless steel sinteredin the presence of a copper based additive," Materials Letters, vol. 61, pp. 10-15, 2007.

[8] A. Babakhani, A. Haerian, and M. Ghambari, "On the combined effect of lubrication and compaction temperature on properties of iron-based P/M parts," Materials Science and Engineering A, vol. 437, pp. 360-365, 2006.

[9] Höganäs, Handbook for warm compaction, Sweden: Höganäs AB, 1998.

[10] A. K. Ariffin, and M. M. Rahman, "Warm metal powder compaction process," Advances in Materials Processing, vol. 1, pp. 159-195, 2003.

[11] A. Bejarano, M. D. Riera, and J. M. Prado, "Simulation of the compaction process of a two-level powder metallurgical part," Journal of Materials Processing Technology, vol. 143-144, pp. 34-45, 2003.

[12] M. M. Rahman, "Themomechanical modelling of powder compaction process," M. Sc. thesis, Universiti Kebangsaan Malaysia, Bangi, Malaysia, 1998.

[13] H. A. Al-Qureshia, M. R. F. Soares, D. Hotza, M. C. Alves, and A. N. Klein, "Analyses of the fundamental parameters of cold die compaction of powder metallurgy," Journal of Materials Processing Technology, vol. 199, pp. 417-424, 2008.

[14] S. M. Tahir, and A. K. Ariffin, "Simulation of crack propagation in metal powder compaction," International Journal of Computational Methods in Engineering Science and Mechanics, vol. 7, pp. 293-302, 2006.

[15] R. S. Ransing, D. T. Gethin, A. R. Khoei, P. R. Mosbah, and W. Lewis, "Powder compaction modelling via the discrete and finite element method," Materials \& Design. vol. 21(4), pp. 263-269, 2000.
[16] H. A. Al-Qureshi, A. Galiotto, and A. N. Klein, "On the mechanics of cold die compaction for powder metallurgy," Journal of Materials Processing Technology, vol. 166, pp. 135-143, 2005.

[17] M. Hehenberger, and J. E. Crawford, "A predictor method for finite element analysis of sliding friction," Scandinavia Journal of Metallurgy, vol. 12, pp. 285-288, 1983.

[18] G. F. Bocchini, G. Cricri, and R. Esposito, "Friction effects in metal powder compacting part two: experimental result," Advances in Powder and Particulate Materials, vol. 1(2), pp. 141-151, 1996.

[19] W. J. Ullrich, K. Patel, R. Gotham, and J. V. Marino, "Recent developments in non ferrous powder," International Journal Powder Metallurgy, vol. 30(2), pp. 109-116, 1994.

[20 A. K. Ariffin, A. Jumahat, and M. M. Rahman, "The simulation of die movement in designing P/M parts," in National Design Seminar Malaysia, 2001

[21] H. Vidarsson, "Lubricant for metallurgical powder composition," U. S. Patent 6605251, Dis. 8, 1997.

[22] S. Deepak, and D. Apelian, "Control strategy for de-lubrication of $\mathrm{P} / \mathrm{M}$ compacts, International Journal of Powder Metallurgy, vol. 38(3), pp. 71-79, 2002.

[23] A. Simchi, "Effects of lubrication procedure on the consolidation, sintering and microstructural features of powder compacts," Materials and Design, vol. 24, pp. 585-594, 2003.

[24] K. Yamaguchi, N. Takamura, S. Imatani, "Compaction and sintering characteristics of composite metal powders," Journal of Material Processing Technology, vol. 63, pp. 364-369, 1997.

[25] K. Othmer, Encyclopedia of Chemical Technology, New York: John Wiley \& Sons, 1992.

[26] J. M. Zazula. (1997). On graphite transformation at high temperature and pressure induced by absorption of the LHC beam. [online]. Available http://lbruno.home.cern.ch/lbruno/documents/Bibliography/LHC_No te $78 . \mathrm{pdf}$

[27] J. F. Shackelford, Materials Science for Engineers, USA: Prentice Hall, 2000.

[28] G. E. Dieter, Mechanical Metallurgy, United Kingdom: McGrawHill, 1998.

[29] M. M. Rahman, A. K. Ariffin, S. S. M. Nor, and H. Y. Rahman, "Powder material parameters establishment through warm forming route," Materials and Design, vol. 32 (1), pp. 264-271, 2011.

[30] C. Shun-hua, L. Xin-ping, L. Jiong-yi, X. Zhan, and C. Zhi-yong, "Key parameters for low temperature warm compaction of high density iron-based P/M materials," Journal of Central South University of Technology, vol. 12(4), pp. 359-365, 2005.

[31] C. Shun-hua, H. Bai-yun, Q. Xuan-hui, and Y. Jian-hong, "Densification mechanism of warm compaction and powder mixture designing rules," Journal of Central South University of Technology, vol. 7(1), pp. 4-6, 2000.

[32] R. Tejedor, R. R. Baracaldo, J. A. Benito, J. Caro, and J. M. Cabrera, "Influence of the carbon content on the strain rate sensitivity of nanocrystalline steels," Scripta Materialia, vol. 59, pp. 631-634, 2008

[33] L. A. Dobrzanski, A. Kloc, G. Matula, J. Domagała, and J. M. Torralba, "Effect of carbon concentration on structure and properties of the gradient tool materials," Journal of Achievements in Materials and Manufacturing Engineering, vol. 17(1-2), pp. 45-48, 2006.

[34] R. Narayanasamy, V. Anandakrishnan, and K. S. Pandey, "Effect of carbon content on instantaneous strain-hardening behaviour of powder metallurgy steels," Materials Science and Engineering A., vol. 497, pp. 505-511, 2008.

[35] R. Narayanasamy, V. Anandakrishnan, and K. S. Pandey, "Effect of carbon content on workability of powder metallurgy steels," Materials Science and Engineering A, vol. 494, pp. 337-342, 2008.

[36] A. Fujiki, "Present state and future prospects of powder metallurgy parts for automotive applications," Materials Chemistry and Physics, vol. 67, pp. 298-306, 2001. 